Rev. Inst. Flor. v. 28 n. 2 p. $103-109$ dez. 2016

http://dx.doi.org/10.24278/2178-5031.201628202

ISSN impresso 0103-2674/on-line 2178-5031

\title{
ANÁLISE DO DESENVOLVIMENTO INICIAL DE MUDAS DE Tabebuia impetiginosa SUBMETIDAS A DIFERENTES TIPOS DE SUBSTRATOS ${ }^{1}$
}

\section{ANALYSIS OF THE INITIAL DEVELOPMENT OF Tabebuia impetiginosa SEEDLINGS SUBMITTED TO DIFFERENT TYPES OF SUBSTRATES}

\author{
Thais Pollon ZANATTA ${ }^{2,4}$; Edison Bisognin CANTARELLI'; \\ Daniele FONTANA ${ }^{2}$; Patricia BREZOLIN²; Carolina TRENTIN²; \\ Diandra DELLA FLORA ${ }^{2}$; Carla Janaina WERNER ${ }^{2}$
}

\begin{abstract}
RESUMO - A produção de mudas de espécies florestais nativas encontra diversas dificuldades, entre as quais a maior está relacionada às diferentes combinações de substratos, pois influenciam no vigor, desenvolvimento e sanidade das mesmas. Desse modo, o objetivo do trabalho foi avaliar o desenvolvimento de mudas de Tabebuia impetiginosa, utilizando seis substratos facilmente encontrados nas propriedades rurais. O trabalho foi conduzido na Universidade Federal de Santa Maria, Campus de Frederico Westphalen - RS. $\mathrm{O}$ delineamento utilizado foi inteiramente casualizado, com seis tratamentos, sendo eles 1) $45 \%$ de solo peneirado (SP) $+45 \%$ areia (A) $+10 \%$ de vermiculita (V); 2) $45 \% \mathrm{SP}+45 \% \mathrm{~A}+10 \% \mathrm{~V}+108 \mathrm{~g}$ de osmocote (OS); 3) $35 \% \mathrm{SP}+35 \% \mathrm{~A}+10 \% \mathrm{~V}+20 \%$ composto orgânico de aves (COA); 4) 35\% SP + 35\% A + 10\% V + 20\% composto orgânico de esterco bovino (COEB); 5) 35\% SP + 35\% A + 10\% V + 20\% composto orgânico suíno (COS); 6) $35 \% \mathrm{SP}+35 \% \mathrm{~A}+10 \% \mathrm{~V}+20 \%$ composto orgânico de champignon (COC), realizado em vasos, com seis repetições. As avaliações consistiram na mensuração da altura de planta - AP e o diâmetro do colo - DC. Para a variável AP e DC, os tratamentos com adição de "osmocote" apresentou o melhor resultado, não diferindo dos demais tratamentos. Os resultados evidenciam que a adição de compostos orgânicos preparados a partir do material disponível nas propriedades resulta em benefícios à qualidade das mudas, sendo uma alternativa rentável para pequenos produtores.
\end{abstract}

Palavras-chave: ipê-roxo; substrato orgânico; osmocote; produção de mudas.

\footnotetext{
${ }^{1}$ Recebido para análise em 19.04.2016. Aceito para publicação em 08.08.2016.

${ }^{2}$ Acadêmica do curso de Agronomia da Universidade Federal de Santa Maria, Campus Frederico Westphalen, Linha 7 de Setembro, s/n, BR 386 km 40, 98400-000 Frederico Westphalen, RS, Brasil .

${ }^{3}$ Universidade Federal de Santa Maria, Departamento de Engenharia Florestal, Campus Frederico Westphalen, Linha 7 de Setembro, s/n, BR 386 km 40, 98400-000 Frederico Westphalen, RS, Brasil

${ }^{4}$ Autor para correspondência: Thais Pollon Zanatta - thais_2zanatta@hotmail.com
} 
ABSTRACT - The production of seedlings of native forest species presents many difficulties, the largest of them is related to the different combinations of substrates, because they influence the vigor, development and sanity of the seedlings. Thus, the objective of this study was to evaluate the development of Tabebuia impetiginosa seedlings, using six substrates easily found on farms. The work was conducted at the Universidade Federal de Santa Maria, Campus Frederico Westphalen - RS The design was completely randomized with six treatments, namely 1) $45 \%$ of sifted soil (SP) $+45 \%$ sand (A) $+10 \%$ vermiculite (V); 2) $\mathrm{SP}+45 \% 45 \% \mathrm{~A}+10 \% \mathrm{~V}+108 \mathrm{~g}$ of osmocote (OS); 3) $35 \% \mathrm{SP}+35 \% \mathrm{~A}+10 \% \mathrm{~V}+20 \%$ organic poultry compound (COA); 4) $35 \% \mathrm{SP}+35 \% \mathrm{~A}+10 \% \mathrm{~V}+20 \%$ organic compost manure (BEOC); 5) $35 \% \mathrm{SP}+35 \% \mathrm{~A}+10 \% \mathrm{~V}+20 \%$ pig organic compound (COS); 6) $\mathrm{SP} 35 \%+35 \%+10 \%+20 \% \mathrm{~V}$ champignon organic compound (COC), performed in pots, with six replicates. Evaluations consisted in the measurement of plant height - AP and stem diameter - DC. For the variable AP and DC, the treatments with the addition of "osmocote" showed the best result, not differing from other treatments. The results show that the addition of organic compounds prepared from the material available on the properties results in benefits to the quality of the seedlings being a cost effective alternative for small producers.

Keywords: ipê roxo; organic substrate; osmocote; seedling production.

\section{INTRODUÇÃO}

A espécie Tabebuia impetiginosa, pertence família Bignoniaceae, vulgarmente conhecida como ipê-roxo, tem sua ocorrência em quase todo o território nacional nacional, no Paraguai e na Argentina, entre outros países. No Rio Grande do Sul, é uma espécie característica da mata latifoliada do Alto Médio Uruguai, onde apresenta distribuição irregular e descontínua. Essa espécie é uma árvore caducifólia, comumente atinge entre 10 a $35 \mathrm{~m}$ de altura e 30 a $40 \mathrm{~cm}$ de diâmetro. O tronco é reto, cilíndrico e frequentero. O troco è reto, cilingico e frequente tortuoso. As folhas são opostas digitadas, possu flores grandes, rosadas a lilás, tubulares, vistosa reunidas em panícula terminal. $O$ fruto é síliqu cilindrico estreito, deiscente, com numerosa sementes, sendo sua dispersão anemocórica (Reiz et al., 1988; Carvalho, 1994)

Segundo Jankowsky et al. (1990) a madeira do gênero Tabebuia é considerad "madeira-de-lei", muito resistente e uma das melhores $\mathrm{d}$ flora sul brasileira. Usada na construcão civil e nava lém de possuir um acabamento fino e belo. Possui uso melicinal sendo a casca utiliza Possuil uso medicina, sendo a casca utilizada como e comizan e contra ín e contra diabetes. Além dessas características, (Carvalho, 2003).

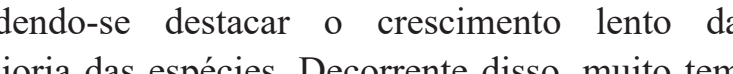
pecorrente disso, muito tem pesquisado para favorecer a produção com qualidade, em menor espaço de tempo e em condições acessíveis aos pequenos e médios produtores rurais, sendo este o público mais interessado neste tipo de insumo (Cunha et al., 2005).

ipê-roxo pode ser plantado: a) em pleno sol em plantio puro, com comportamento satisfatório quando plantado em solos férteis, porém com forma inadequada, b) em plantio misto, associado com espécies pioneiras e secundárias, visando melhoria na forma do fuste e em vegetação matricial arbórea, em faixas na vegetação secundária e plantado em linhas
Não há conhecimento das exigências nutricionais da maioria das espécies nativas, apesar da existência de formulações de adubações, em que estas estão restritas à produção de muda comerciais e a um número pequeno de silvicultores. Por isso, é de extrema importância o estudo de substratos alternativos e recipientes adequados, visando baratear os custos de produção e tornar - viveirismo atividude acesśvel a todos os produtores rurais, interessados em recompor suas áreas ou explorar alguma atividade silvicultura (Jesus, 1997; Sturion e Antunes, 2000). Devido à poucas opções no mercado, é crescente a busca dos produtores por substratos alternativos, proporcionando um mercado diferenciado e lucrativo (Evangelista et al., 2016). Entre os diversos materiais utilizados como substratos, é comum a recomendação de misturas a partir de solo (Vinadé et al., 2016) e outros componentes (Silva et al., 2008) Para se obter mudas de qualidade, é necessária a utilização de técnicas adequadas de formação e, dentre os fatores importantes, destacam-se as propriedades do substrato, nível de nutrição e disponibilidade de água às muda (Navroski et al., 2015). Deve ser uniforme em sua composição, ter baixa densidade, se poroso, apresentar adequada capacidade de retenção de água, deidade de troca de cátions - CTC, ser isento de pragas, de organismo patogênicos e de sementes de plantas daninhas.

Tabela 1. Composição dos substratos nos tratamentos.

Table 1. Substrate compositions in treatments.

Embora o equilíbrio nutricional seja a situação desejável, nem sempre é possível conciliar condições ideais com viabilidade econômica (Campinhos Junior e Ikemori, 1983; Gonçalves, 1995).

Materiais orgânicos têm sido utilizados para a formulação de substratos na produção de mudas, surgem como uma alternativa para diminuir os custos com a adubação química. Contudo, torna-se necessário determinar os substratos mais indicados para o desenvolvimento de cada espécie vegetal, visando ao fornecimento adequado de nutrientes (Guimarães et al., 2006). Desse modo, o objetivo do presente trabalho foi avaliar o desenvolvimento inicial de mudas de ipê-roxo (Tabebuia impetiginosa) utilizando seis substratos orgânicos de fácil acesso em propriedades rurais.

\section{MATERIAL E MÉTODOS}

O trabalho foi conduzido no viveiro florestal da Universidade Federal de Santa Maria, Campus Frederico Westphalen - RS, e o experimento conduzido em vasos com volume de três litros, distribuídos aleatoriamente sob bancada. As condições de temperatura e umidade foram controladas pelo sistema de irrigação da estufa $\mathrm{O}$ delineamento utilizado foi inteiramente casualizado, com seis tratamentos e seis repetições, totalizando 36 unidades amostrais (Tabela 1)

\begin{tabular}{ll}
\hline Tratamentos & Composição \\
\hline 1 & $45 \%$ solo argiloso peneirado $+45 \%$ areia e $10 \%$ vermiculita \\
2 & $45 \%$ solo argiloso peneirado $+45 \%$ areia $+10 \%$ vermiculita +108 g de osmocote \\
3 & $35 \%$ solo argiloso peneirado $+35 \%$ areia $+10 \%$ vermiculita $+20 \%$ de composto orgânico de aves \\
4 & $35 \%$ solo argiloso peneirado $+35 \%$ areia $+10 \%$ vermiculita $+20 \%$ de composto orgânico de esterco bovino \\
5 & $35 \%$ solo argiloso peneirado $+35 \%$ areia $+10 \%$ vermiculita $+20 \%$ de composto orgânico de esterco suíno \\
6 & $35 \%$ solo argiloso peneirado $+35 \%$ areia $+10 \%$ vermiculita $+20 \%$ de composto orgânico para champignon \\
\hline
\end{tabular}


Após a mistura dos componentes de cada tratamento, os substratos foram acondicionados em vasos plásticos e procedido o transplante de mudas de ipê-roxo (com 90 dias após semeadura), em abril de 2014. No dia do traplante, sealiza), en abril de 2014. No dia do transplante, realizou-se a mensuração de suas caracteristicas físicas (altura

e diâmetro de colo), e avaliou-se o incremento
seu crescimento até 150 dias após transplante.

As avaliações realizadas consistiram n mensuração da altura de planta $(\mathrm{cm})$, com auxílio de uma régua desde o colo da planta até a ultima gema apical do ramo principal, e o diâmetro do colmo (mm), com o auxílio de um paquímetro digital. Para a obtenção da massa seca das mudas, separou-se a parte aérea das raízes, sendo colocada em sacos de papel e secas em estufa à $72{ }^{\circ} \mathrm{C}$ at atingir peso constante, em seguida foram pesadas em balança de precisão

As médias referentes à massa seca das plantas foram apresentadas em gramas tratamento ${ }^{-1}$.
Para as variáveis altura de planta e diâmetro do colo, os dados obtidos foram submetidos à an dise da variância, testando a interação pelo teste $\mathrm{F}(5 \%)$ as médias comparadas pelo teste de Tukey a $5 \%$ de probabilidade de erro.

\section{RESULTADOS E DISCUSSÃO}

Os dados referentes à massa seca das plantas de ipê-roxo apresentaram diferenças entre os tratamentos submetidos, sendo que o tratamento 2 apresentou superioridade em ambas as variávei analisadas (parte aérea e sistema radicular) O tratamento 1, que continha apenas solo, areia e vermiculita apresentou os menores valore de massa seca. Os demais tratamentos $(3,4,5$ e 6$)$ acrescidos de material orgânico mostraram-se semelhantes nas características avaliadas (Figura 1)

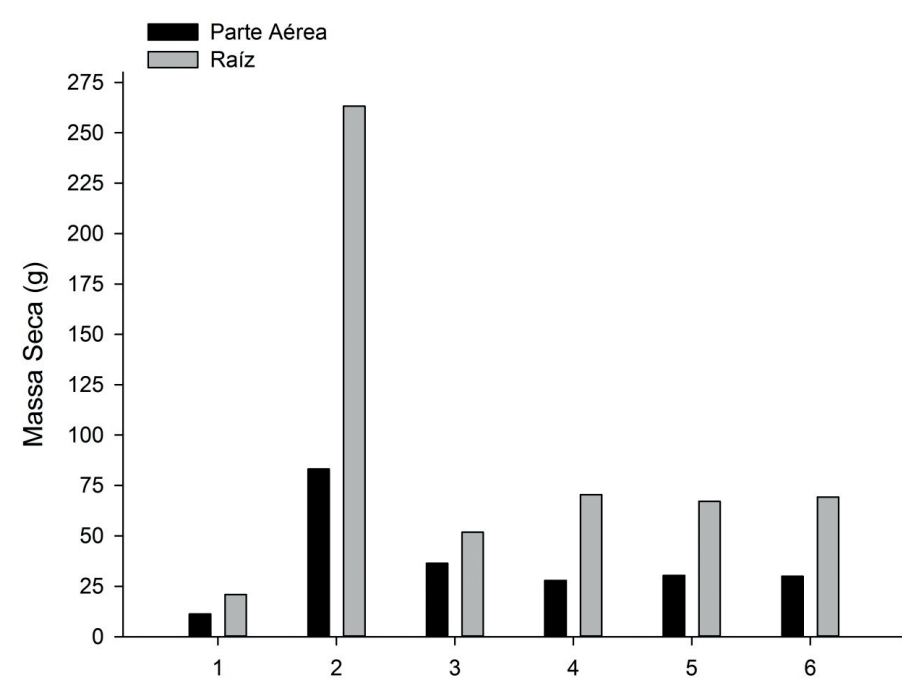

Tratamentos

Figura 1. Massa seca de parte aérea e raiz de mudas de ipê-roxo (Tabebuia impetiginosa) após 150 dias do transplante, nos diferentes tipos de tratamento. (Ver composição dos substratos na Tabela 1).

igure 1. Dry mass of aerial part and root of ipê-roxo seedlings (Tabebuia impetiginosa) after 150 days of transplant in different types of treatment. (See the composition of the substrates in Table 1).

O "osmocote" (Tratamento 2) é um substrato orgânico que possui em sua formulação adições de nitrogênio, fósforo e potássio a concentração 14-14-14, possui liberação enta de nutrientes, devido a uma metaça (Wombrana (Wilsen Neto e Botrel, 2009). A unider a (Wilsen Neto e Botrel, 2009). A umidade e a

A adição de esterco bovino ao substrato favorece o aumento da matéria seca das raízes de plantas, conforme verificado para a espécie Hancornia speciosa (Silva et al., 2009), e o aumento da matéria seca da parte aérea, como observado para a espécie Cassia grandis (Carvalho Filho, 2002)

Para a variável altura de planta, foi possivel observar que o tratamento 2 apresento os maiores valores, destacando-se dos demais, ñ̃o difeiu estatisticante dos tamento 5. 0 menor valor de altira fiv vificado para e 6. O menor valor de altura for verifcado para na sua composição (Tabela 2).

Tabela 2. Incremento de altura $(\mathrm{cm})$ e diâmetro do colo $(\mathrm{cm})$ de mudas de ipê-roxo (Tabebuia impetiginosa) submetidas a diferentes tipos de substratos. (Ver composição dos substratos na Tabela 1).

Table 2. Height increment $(\mathrm{cm})$ and stem diameter $(\mathrm{cm})$ of ipê-roxo seedlings (Tabebuia impetiginosa) submitted to different types of substrates. (See substrates composition in Table 1).

\begin{tabular}{ccc}
\hline Tratamentos & Altura $(\mathrm{cm})$ & Diâmetro $(\mathrm{mm})$ \\
\hline 1 & $8,12 \mathrm{c}$ & $3,65 \mathrm{~b}$ \\
2 & $49,95 \mathrm{a}$ & $8,48 \mathrm{a}$ \\
3 & $42,25 \mathrm{ab}$ & $8,68 \mathrm{a}$ \\
4 & $26,40 \mathrm{bc}$ & $8,09 \mathrm{a}$ \\
5 & $34,83 \mathrm{ab}$ & $6,28 \mathrm{ab}$ \\
6 & $29,46 \mathrm{abc}$ & $8,18 \mathrm{a}$ \\
\hline $\mathrm{CV}(\%)$ & 19,91 & 13,91 \\
\hline
\end{tabular}

Médias seguidas de mesma letra na coluna não diferem pelo teste de Tukey a 5\% de probabilidade. Means followed by the same letter in the column do not differ by Tukey test at $5 \%$ probability.

A adição de "osmocote" proporcionou aumento no desenvolvimento de Schinus terebinthifolius, evidenciando acréscimo na altura das plantas (Caldeira et al., 2008). Plantas de Hymenaea courbaril, produzidas em substrato de solo + areia + esterco, apresentaram maiores médias de altura de planta do que as cultivadas em solo + areia (Carvalho Filho et al., 2003). Contudo, mudas de uvaia, produzidas em latossolo + areia + cama de frango, apresentaram maior comprimento de parte aérea, número de folhas e área foliar (Scalon e Jeromine, 2013), corroborando com os resultados encontrados no presente estudo.

Sugere-se que os resultados obtidos neste trabalho foram influenciados pela presença de "osmocote" e esterco na formulação do substrato, pois o esterco apresenta rápida mineralização. Resultados semelhantes foram obtidos po Cunha et al. (2005) com mudas de ipê-roxo (Tabebuia impetiginosa), quando utilizaram esterco bovino e de aves.
Alguns autores têm comprovado que a adição de composto orgânico aos substratos utilizados para produção de mudas resulta em benefícios. Segundo Correia et al. (2001), o esterco é um componente orgânico que, juntamente com outros, melhora as condições físicas do substrato, como aeração e drenagem, além de ser rico em nutrientes, que são rapidamente liberados para as plantas. Gomes et al. (2002) afirmam que a altura de planta apresenta boa variável para avaliação da qualidade de mudas, sendo estas características fáceis e viáveis de mensuração, além de não serem destrutíveis para as mudas.

O maior crescimento em diâmetro do colo foi observado no tratamento 3 com esterco de aves, porém este não diferiu estatisticamente dos tratamentos 2, 4, 5 e 6 , mas foi superio ao tratamento 1 , que consistia em substrato não acrescido de material orgânico (Tabela 1). transplante até a avaliação fin enham ocorrido temperaturas elevadas altas umidade controlada, justifica-se a melhor respost do tratamento com a presença do "osmocote". 
Plantas de Amburana cearenses apresentaram o diâmetro do caule mais elevado quando submetido a tratamentos contendo matéria orgânica na forma de esterco, poŕm ñ̃o obtiverma maiores teores de matéria seca (Q e.roztiveram 2012). Contudo, para a 2012). Contudo, para algunas especies arboreas, o substrato orgânico não é o mais indicado por não influenciar significativamente no acúmul de matéria seca (Angelin, 2007). Ainda segundo Souza et al. (2006) e Carneiro (1995), o diâmetro do caule é item fundamental para a avaliação do potencial de sobrevivência e crescimento pós-plantio de mudas de espécies florestais, em que, dentro de uma espécie, as plantas com maior diâmetro apresentam maior sobrevivência, por apresentarem capacidade de formação de crescimento de novas raízes.

Substratos compostos por solo + esterco bovino apresentaram melhores respostas para desenvolvimento de mudas de Mimosa caesalpiniifolia (Rogrigues, 2011). A adição de esterco bovino ao substrato também se mostrou satisfatória para incremento do diâmetro do colo de plantas em trabalho realizado por Melo Junior (2013), e no realizado por Cunha et al. (2005) com mudas de ipê-roxo (Tabebuia xiquexique), alcançando diâmetro de $3,9 \mathrm{~cm}$

\section{CONCLUSÃO}

Para a variável altura de planta, o tratamento com a adição de osmocote apresento os melhores resultados.

Para o diâmetro de colo, o tratamento com esterco de aves proporcionou os melhores resultados.

Os resultados evidenciam ainda que adição de compostos orgânicos, de baixo custo, preparados a partir do material disponível nas propriedades rurais, resultam em benefícios qualidade das mudas de Tabebuia impetiginosa consequentemente, numa alternativa rentível pa

\section{REFERÊNCIAS BIBLIOGRÁFICAS}

ANGELIM, A.E.S. et al. Germinação e aspecto morfológicos de plantas de umburana de cheiro (Amburana cearensis) encontradas na região do Vale do São Francisco. Revista Brasileira de Biociências, v. 5, n. 2, p. 1062-1064, 2007.
CALDEIRA, M.V.W. et al. Composto orgânico na produção de mudas de aroeira vermelha. Scientia Agraria, v. 9, n. 1, p. 27-33, 2008

CAMPINHOS JÚNIOR, E.; IKEMORI, Y.K. Introducão de novas técnicas na producão de mudas de essências florestais. Silvicultura, v. 8 , n. 28, p. 226,1983 .

CARNEIRO, J.G.A. Produção e controle de qualidade de mudas florestais. Curitiba: UFPR FUPEF; Campos: UENF, 1995. $451 \mathrm{p}$.

CARVALHO, P.E.R. Espécies florestais brasileiras: recomendações silviculturais, potencialidades uso da madeira. Colombro: Embrapa-CNPF; Brasília, DF: EMBRAPA-SPI, 1994. 640 p

Espécies arbóreas brasileiras. Colombo: Embrapa Florestas, 2003. v. 1.

CARVALHO FILHO, J.L. Produção de mudas de Cassia grandis L. em diferentes ambientes, recipientes e misturas de substratos. Revista Ceres, v. 49, n. 284, p. $341-352,2002$.

et al. Produção de mudas de jatobá Hymenaea courbaril L.) em diferentes ambientes, recipientes e composição desubstratos. Revista Ceres, v. 9, n. 1, p. 109-118, 2003

CORREIA, D.; CAVALCANTI JÚNIOR, A.T.; COSTA, A.M.G. Alternativas de substratos para a formação de portaenxertos de gravioleira (Annona muricata) em tubetes. Fortaleza: Embrapa Agroindústria Tropical, 2001. 3 p. (Comunicado Técnico, 67).

CUNHA, A.O. et al. Efeitos de substratos e das dimensões dos recipientes na qualidade das muda de Tabebuia impetiginosa (Mart. ex D.C.) Stand Revista Árvore, v. 29, n. 4, p. 507-516, 2005.

EVANGELISTA, A.W.P. et al. Seedling production of Jatropha curcas in substrates fertilized with lithothamnium. Bioscience Journal, v. 32, n. p. 132-139, 2016.

GOMES, J.M. et al. Parâmetros morfológicos na avaliação da qualidade de mudas de Eucalyptus grandis. Revista Árvore, v. 26, n. 6, p. 515-523, 2002.
GONÇALVES, J.L.M. Recomendações de adubação para Eucalyptus, Pinus e espécies típicas da Mata Atlântica. Piracicaba: ESALQ 1995. 15 p. (Documentos florestais, 23).

GUIMARÃES, M.M.B. et al. Produção de muda de mamoneira em substrato contendo diferentes resíduos orgânicos e fertilizantes minerais In: CONGRESSO BRASILEIRO DE MAMONA, 2., 2006, Aracaju.. Anais... Aracaju: EMBRAPA, 2006. v. 2.

JANKOWSKY, I.P et al Madeiras brasileiras. Caxias do Sul: Spectrum, 1990. v. 1, p. 172.

JESUS, B.M. Morfologia de sementes, germinação e desenvolvimento de mudas de angico de bezerro (Piptadenia obliqua (Pers.) Macbr.). 1997. 81 f. Dissertação (Mestrado en Produção Vegetal) - Universidade Federal da Paraíba, Areia.

MELO JUNIOR, C.J.A.H. de. Efeito do esterco bovino na composição de substrato para produção de mudas de três espécies florestai da Mata Atlântica. 2013. 37 f. Trabalho de Conclusão de Curso - Universidade Federal Rural do Rio de Janeiro, Seropédica.

NAVROSKI, M. et al. Influência do hidroge no crescimento e no teor de nutrientes das mudas de Eucalyptus dunnii. Floresta, v. 45, n. 2, p. 315-328, 2015.

QUEIROZ, J.E. et al. Efeito de diferentes substrato no desenvolvimento inicial do cumaru (Amburana cearensis (Arr. Cam.) A.C. Smith). Revista Verde, v. 7, n. 1, p. 45-49, 2012.

REITZ, R.; KLEIN, R.M.; REIS, A. Projeto madeira do Rio Grande do Sul. Porto Alegre: Secretaria de Agricultura e Abastecimento, 1988. $524 \mathrm{p}$.

RODRIGUES, R.D. Crescimento e qualidade de mudas de sabiá (Mimosa caesalpiniifolia de Conclusão de Curso - Universidade Federal de Campina Grande, Patos.
SCALON, S.P.Q.; JEROMINE, T.S. Substratos e níveis de água no potencial germinativo de sementes de uvaia. Revista Arvore, $v$

SGARBI, F. et al. Influência da aplicação de fertilizante de liberação controlada na produção de mudas de um clone de Eucalyptus urophylla. In: SIMPÓSIO SOBRE FERTILIZAÇ̃̃O NUTRIC̃̃O FLORESTAL, 2, 1999, PIFCic E A

SILVA, E.A. et al. Germinação da semente producão de mudas de cultivares de alface em substratos Semina: Ciência v. 29 , p. $245-254,2008$

et al. Efeito de diferentes substratos na produção de mudas de mangabeira (Hancornia speciosa). Revista Brasileira de Fruticultura, v. 31, n. 3, p. 925-929, 2009.

SOUZA, C.A.M. et al. Desenvolvimento em campo de espécies florestais em diferentes condições de adubação. Ciência Florestal, v. 16 n. 3, p. $243-249,2006$

STURION, J.A.; ANTUNES, B.M.A. Produção de mudas de espécies florestais. In: GALVÃO, A.P.M. Reflorestamento de propriedades rurais para fins de produtivos e ambientais. Colombo: EMBRAPA-CNPF, 2000. p. 125-150.

VINADÉ, C.E.R. et al. Avaliação do desenvolvimento de mudas de Ilex paraguariensis (erva-mate) em diferentes composições de substratos. In: SALÃO INTERNACIONAL DE ENSINO, PESQUISA E EXTENSÃO, 8., 2016. Anais. Bagé: Universidade Federal do Pampa, 2016.

WILSEN NETO, A.; BOTREL, M.C.G. Doses de fertilizante de liberação lenta na produção de mudas de Pinus. Agrarian, v. 2, n. 3, p. 65-72, 2009. 